\title{
PROFILE OF INTENSIVE CARE UNIT ADMISSION AND OUTCOMES OF MEDICAL AND SURGICAL PATIENTS AT A TERTIARY GOVERNMENT HOSPITAL: A 5 YEAR TREND ANALYSIS
}

\author{
SHAKERA AHMED ${ }^{1}$, OMAR FARUQUE YUSUF², AKM SHAMSUL ALAM ${ }^{3}$, ANISUL AWAL $^{4}$
}

\begin{abstract}
:
Background: The intensive care unit (ICU) is that part of the hospital where critically ill patients that require advanced airway, respiratory and haemodynamic supports are usually admitted. Intensive care unit admissions which aim at achieving an outcome better than if the patients were admitted into other parts of the hospital however come at a huge cost to the hospital, the personnel and patients' relations.
\end{abstract}

Objective: To audit the 5 year bed occupancy rate and outcome of medicine and surgical patients admitted into the ICU of the Chittagong Medical College Hospital, Chittagong, Bangladesh.

Design: A 5 years retrospective study (Record review) from January 2012 to December 2016. Method: Data were extracted from the ICU records of the patient and analyzed.

Results: During this study period, the frequency of admission into ICU was significantly more $(p<0.001)$ from medical discipline $(55.20 \%)$ than surgical disciplines $(44.80 \%)$. The incidence of survival was significantly lower ( $p<0.001)$ from medical discipline $(37.68 \%)$, than from surgical disciplines (49.05\%). Occurrence of total ventilatory support provided in all disciplines was $60.32 \%$ and it was significantly higher for the surgical patients. Overall mortality rate was $57.23 \%$.

Conclusion: During prioritizing the patients for ICU admission surgical cases should get preference. It is primarily necessary to optimize patient to doctor ratio and patient to nurse ratio and providing the service by critical care physicians ("intensivists") to reduce the mortality rate of ICU.

Received: 12 November 2017

Accepted: 10 June 2018

DOI: http://dx.doi.org/10.3329/bjmed.v29i2.37939

\section{Background:}

Intensive care units (ICUs) and multi-disciplinary team management have evolved improving the survival of critically ill patients ${ }^{1-3}$. It is a special department of tertiary hospitals for patients with the most severe and life threatening conditions who constantly require intensive monitoring, support from specialized equipment and easy access to medications in order to maintain normal physiological functions ${ }^{4}$.

The earliest attempt at grouping unstable patients started in the 1930s in the form of a post-operative recovery room. The concept of intensive care units (ICU) dates back to the epidemic of poliomyelitis in the early 1950s with the use of long term mechanical ventilation ${ }^{5,6}$. The modern ICU has developed from the fusion of lessons learned from respiratory and coronary care with continued momentum provided by the clinical and technological development in resuscitation, pharmacological and mechanical circulatory support and advances in renal replacement therapy, respiratory failure, cerebral oedema and multi-organ failure 7 .

Today, Intensive care units (ICUs) of most hospitals in developed countries have become separate departments staffed by career intensive care physicians or intensivists from various fields of medicine ${ }^{5}$. In Bangladesh, however, ICUs are still part of the anaesthesia department and critical care constitutes a substantial part of the workload and responsibilities of anesthetists ${ }^{8}$.

The burden of critical illness in low-income countries like Bangladesh is large and likely to increase with growing urbanization, emerging epidemics and access to hospitals ${ }^{9-11}$. Therefore, data on critical care

1. Assistant Professor, Department of Surgery, Chittagong Medical College,

2. Professor and Ex Head, department of Surgery, Chjttagong Medical College.

3. Professor and Head, department of Anaesthesiolgy, Chittagong Medical College.

4. Assistant Professor, department of Cardiology, Chittagong Medical College.

Correspondence: Dr. Shakera Ahmed, Assistant Professor, Department of Surgery, Chittagong Medical College, email:shakeraahmed12@gmail.com Cell no: 01711307876

Bangladesh J Medicine 2018; 29 : 59-62 
capacity, considering access to both physical resources and health care professionals, are essential for health system planning but generally lacking or difficult to find ${ }^{12}$.

Chittagong Medical College Hospital is 1200 bedded tertiary hospital of Bangladesh with catchments area of population 3.5 million. The Intensive care unit of $\mathrm{CMCH}$ serves the critically ill patients belonging to various disciplines. It was established in 23rd June 2005 and was the second public sector ICU in Bangladesh following DMCH.

It was started as 6 bedded compact unit well equipped for critical care at the highest level and now 12 bedded, located adjacent to the operating theatre complex. EachICU bed is equipped with one mechanical ventilator and one monitor (with facilities of SpaO2, ECG, RR, EtCO2, NIBP and Temp). It has ABG facilities, one color Doppler, one Spiro meter and fibreoptic bronchoscope and USG facilities. The ICU is staffed by 11 consultant anesthetists and trainee doctors at various levels of training. There are 23 nursing staffs, 5 of whom are well-trained intensive care nurses. An admission into ICU is from two sources, the wards and from other ICU of private hospitals and depends on bed availability. There are no formal defined entry criteria to enter into these ICUs. Data regarding outcome in the ICU is well-documented.

Rationing of critical care resources, using admitting diagnosis or scoring tools, can maximize access to critical care services in resource-limited settings. This study will provide updated information about the recent pattern of admission and outcome in our ICU in $\mathrm{CMCH}$, with special emphasis to find out any difference in outcome of surgical and medicine cases. This will contribute to the literature on the provision of intensive care facilities in Bangladesh

\section{Methods and materials:}

.This is a 5 year retrospective study in which data on the number of patients from various departments admitted into ICU, the number of patient required ventilatory support and the mortality of the patients admitted into the Intensive care unit (ICU) of $\mathrm{CMCH}$ from 1 st of January 2012 to 31 st December 2016. The data was obtained from ICU admissions record book. These patients were managed by the anesthetists and the admitting surgeon or physician. The data was recorded on a proforma format sheet designed for the study and data analysis was done using SPSS (Version 23).

\section{Results:}

5 years trend of ICU bed occupancy by different discipline is shown in Figure 1. It showed that admission from medicine department is increasing gradually from 106 in 2012 to 284 in 2016. On the other hand number of patient from general surgery is decreasing gradually (94 in 2012 and 52 in 2016).

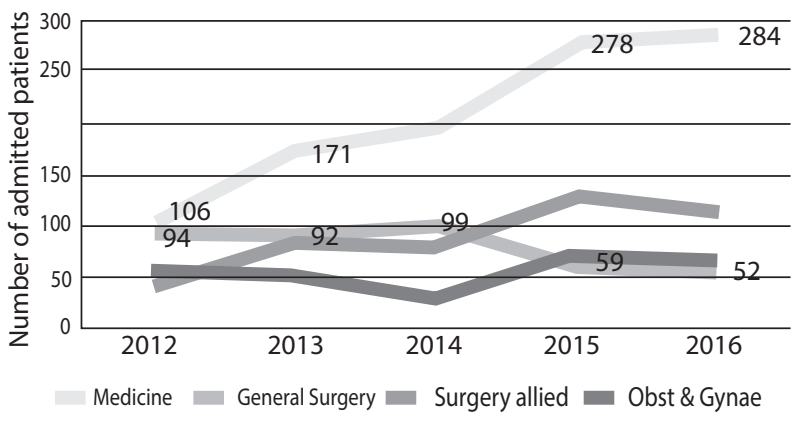

Fig.-1: ICU lad by different discipline

Figure 2 showed the trend of survival among the ICU admitted patients from different discipline. Though the bed occupancy rate was always higher in medicine discipline the survival rate was higher from the patients of general surgery department in the last 5 year.

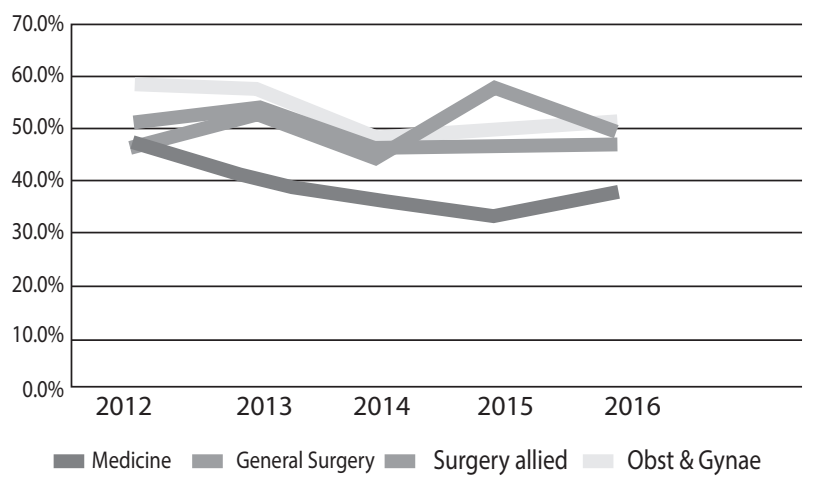

Fig.-2: Survival trends of admitted patients of different discipline

After categorizing the patients in two category medicine and surgery (General surgery, allied surgery and Obstetric \& Gynea), survival rate was always lower in ICU admission from medicine discipline (Figure 3).

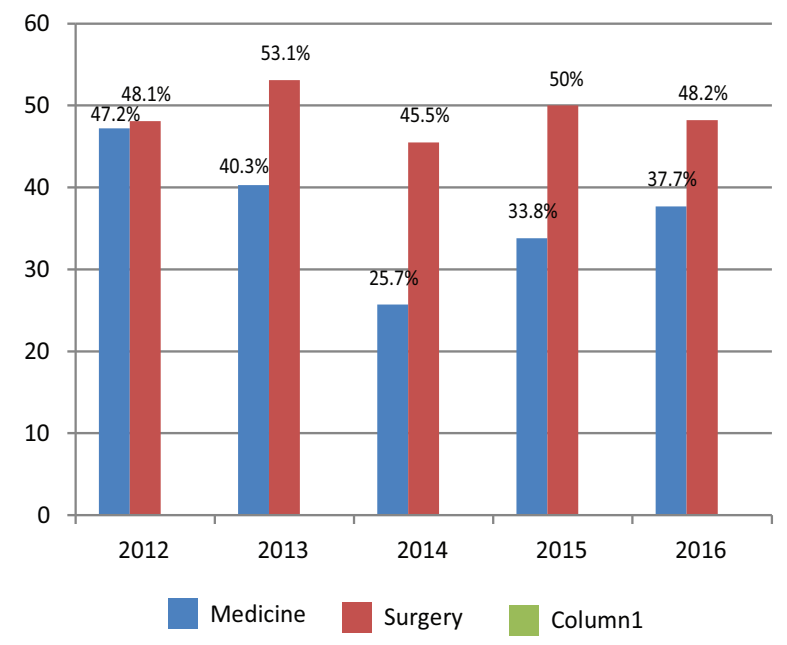

Fig.-3: Percentage of survival among ICU admitted patients of surgery \& medicine in 5 years 
A total 1875 patients were admitted into this ICU during this 5 years period, among them 1035 (55.20\%) were medical patients and $840(44.80 \%)$ were surgical patients. Incidence of survival and mortality rate of study group patients were depicted in Table 1 , which showed that $37.68 \%$ and $62.32 \%$ from medical and $49.05 \%$ and $50.95 \%$ from surgical disciplines and total ICU survival and mortality were $42.77 \%$ and $57.23 \%$ respectively.

Table-1

5 years survival and mortality of study group patients of ICU

\begin{tabular}{lccccc}
\hline Name of discipline & No. of & \multicolumn{2}{c}{ Survived } & \multicolumn{2}{c}{ Death } \\
admitted & patient & N & $\%$ & N & $\%$ \\
\hline Medicine & 1035 & 390 & 37.68 & 645 & 62.32 \\
Surgery & 840 & 412 & 49.05 & 428 & 50.95 \\
\hline Total & 1875 & 802 & 42.77 & 1073 & 57.23 \\
\hline
\end{tabular}

$\chi^{2}=24.011 ; \mathrm{P}<0.0001$. Highly Significant

The number of patients provided ventilatory support in medical discipline were $556(53.72 \%)$, in surgical were 575 (68.45\%), and total ventilatory support provided in all disciplines were $1131(60.32 \%)$, which were shown to the Table-II.

Table-II

Discipline-wise ventilatory support of study group patients $(n=1875)$

\begin{tabular}{lccccc}
\hline $\begin{array}{l}\text { Name of discipline } \\
\text { ventilator }\end{array}$ & $\begin{array}{l}\text { No. of } \\
\text { patient }\end{array}$ & \multicolumn{2}{c}{ Without } & \multicolumn{2}{c}{ Put on } \\
admitted & & $\mathrm{N}$ & $\%$ & $\mathrm{~N}$ & $\%$ \\
\hline Medicine & 1035 & 479 & 46.28 & 556 & 53.72 \\
Surgery & 840 & 265 & 31.55 & 575 & 68.45 \\
\hline Total & 1875 & 744 & 39.68 & 1131 & 60.32 \\
\hline
\end{tabular}

$\chi 2=41.434 ; \mathrm{P}<0.0001$. Highly Significant

\section{Discussion:}

The outcome of intensive care depends not only on the facilities provided in the unit, the skill and timing with which they are administered, but also on the case mix of problems presented by the surgeons and physicians, who make the initial decisions, which results in their patients requiring intensive care ${ }^{13}$. It demands a tremendous amount of time and efforts of the medical and nursing staff to treat and improve survival of the critically ill patients. The type and facilities available influences the variety of critical cases that can be handled ${ }^{14}$.

In our study, medicine specialty is observed to be the highest specialty utilizing the ICU bed spaces in last 5 years, 1035 (55.20\%). Findings are similar with the profile of another tertiary hospital of Chittagong, Chittagong Military Hospital ( $\mathrm{CMH}$ ) where the prevalence of admission into this ICU was more from medical discipline $(59.92 \%)$ than that of other disciplines like surgical $(37.52 \%)$ discipline ${ }^{15}$. This was different from the study done by Abubakar et al. ${ }^{16}$ where there were a total of 114 admissions into their critical care unit in one year and they were majorly surgical patients (66.7\%).

Mortality in intensive care unit patients remains high in all hospitals. Severely ill patients may experience higher mortality rates when assigned to ICU. In other different studies it was found that ICU mortality rate varies between 15 to $44 \%$ depending on the case mix, age, length of stay and organizational aspects of the unit and corresponding mortality in the hospitalized patients was 30 to $42.2 \% 17-19$. In this study it was found that the incidence of mortality was more in medical discipline $(62.32 \%)$ than surgical discipline (50.95\%). and total ICU mortality rate was $57.23 \%$. It is similar with the mortality pattern in $\mathrm{CMH}$, Chittagong, where mortality was more in medical discipline (46.14\%) than surgical discipline (31\%).

The mortality rate in our study compares favorably with others in the country; it is higher than those reported in the developed world, where mortality figures of $18-24 \%$ have been quoted 20,21 . In our study ventilator support was required for $60 \%$ of all ICU admitted patients. It was significantly higher among the patients from surgery discipline $(p<0.001)$. The finding is different from the findings of Hossain et a1. ${ }^{15}$ where it was found that requirement of ventilatory support is much less than that of other ICUs $(45.34 \%)$

From the analysis of the 5 years ICU admission data, trend of admissions is clear. More patients from medicine specialty are admitted but less number of them is survived in comparison to surgical specialty admission and the overall mortality is high in this ICU.

\section{Limitations of the Study}

Although the research has reached its aims there were some unavoidable limitations. First, this is a cross-sectional study and cannot be used to postulate incidence, effects of interventions and follow-up studies. The sampling technique though limited to a tertiary care center would make generalizability of results to the whole country impossibile. This study 
does not provide other outcome measures that can be used to assess quality of intensive care such as mortality within the first $24 \mathrm{~h}$ and mean number of ICU days of stay per survivor. Future research should provide information on detailed analysis on the diagnosis of ICU cases in $\mathrm{CMCH}$ that can allow comparison with other studies. Due to lack of standardization, comparing efficacy of care with even similar ICU studies in developing countries would be difficult and would be more plausible with a prospective study. Also, further study showing annual mortality indices might shed more light on efficacy of care. To allow generalizability, we would have to collate data from other tertiary care centers in the country. However this is impossible at the moment because of limited studies, lack of access to data from other tertiary care centers and lack of communication with physicians located in other tertiary care centers. Future efforts to encourage research and communication amongst tertiary care centers to create a central database registry would be recommended to make this a possibility.

\section{Conclusion}

Survival rate of patients in our ICU is uncomfortably low. However, the survival rate is significantly higher among the patients of surgery department than that of the medicine department. This should be considered during prioritizing the patients for ICU admission.

It is primarily necessary to optimize the patient to doctor ratio and patient to nurse ratio to reduce the mortality rate of ICU. The modern monitoring appliances, including central monitoring system for vital parameters and organ support facilities should be available to reduce the ICU mortality. Finally the ICU should be run by the critical care physicians ("intensivists") because they are psychologically familiar with this situation and developed endurance with ICU milieu and used to provide precise and aggressive treatment, monitoring and intervention of various emergencies which will also decreases the ICU mortality significantly.

\section{References:}

1. Gosselink R, Bott J, Johnson M, Dean E, Nava S, et al. Physiotherapy for adult patients with critical illness: Recommendations of the European Respiratory Society and European Society of Intensive Care Medicine Task Force on Physiotherapy for Critically Ill Patients. Intensive Care Med. 2008; 34: 1188-1199.

2. Van der SM, Beelen A, De Groot IJ. Critical illness polyneuropathy: A summary of the literature on rehabilitation outcome. Disabil Rehabil. 2000; 22: 808-810.

3. Fan E. Critical illness neuromyopathy and the role of physical therapy and rehabilitation in critically ill patients. Respir Care. 2012; 57:933-946.
4. Hinds CJ, Watson D. Planning, organization and management of intensive care. In: A Concise Textbook. 2nd ed. WB Saunders Company Limited, London. 1996

5. Oh TE. Intensive care in Hong kong where now? J Hong kong Med Ass Association. 1992; 44: 57.

6. Review of intensive care in Hong kong where now? J Hong kong med Ass Association 44: 57.

7. Manimala Rao S, Suhasini T. Organization of intensive care unit and predicting outcome of critical illness.Indian journal of anaesthesia. 2003; 47 (5): 328-337.

8. Critical Care Practice: Bangladesh Perspective. From the Desk of the Editor. Bangladesh Crit Care J. 2013; 1: $1-2$

9. Murray CJL, Lopez AD. Measuring the Global Burden of Disease. New England Journal of Medicine. 2013;369: 448-457.

10. Annez PC, Linn JF. An agenda for research on urbanization in developing countries: a summary of findings from a scoping exercise. Geneva: The World Bank. 2010.

11. World Health Organization Ebola Response Team. Ebola virus disease in West 2014;371: 1481-1495.

12. Austin S, Murthy S, Wunsch H, Adhikari NK, Karir $\mathrm{V}$, et al. Access to urban acute care services in highvs. middle-income countries: an analysis of seven cities. Intensive Care Med. 2014;40: 342-352.

13. Intensive care in the United Kingdom: Report from the King's Fund panel. Anaesthesia 44: 428-431.

14. Chalya PL, Gilyoma JM, Dass RM, Mchembe MD, Matasha $M$, et al. Trauma admissions to the Intensive Care Unit at a reference hospital in Northwestern Tanzania. Scand J Trauma Resusc Emerg Med. 2011; 19: 61.

15. Hossain M D, Maruf A A. An Analysis of 1255 ICU Patients at a Tertiary Military Hospital. Bangladesh Crit Care J March 2013; 1: 40-44.

16. Abubakar A, Ojo E, El-Nafaty A, Edomwonyi N. An Audit Of One-Year Intensive Care Practice In A Developing Country. The Internet Journal of Anesthesiology. 2007 Volume 18 Number 2.

17. Kathleen Sebelius. Epidemiology, Prevalence, and Sites of Infections in ICUs: Mortality from ICUacquired infections. Semin Respir Crit Care Med. 2003; 24(1)

18. R.Moreno, P.Morais. Outcome prediction in intensive care: results of a prospective, multicentre, Portuguese study. Intensive Care Med.1997; 23: 177-186.

19. Desikan SD, Bray B, Kurian J, Ali S, Chappel W. Outcome after ICU admission in patients over ninety years old. Anesthesiology 2007; 107: 331.

20. Dragsted L, Qvist J, Madsen M. Outcome from intensive care II. A 5-year study of 1308 patients: Short-term outcome. European Journal of Anaesthesiology. 1989; 6: 131-144.

21. Africa-the first 9 months of the epidemic and forward projections. N Engl J Med British Medical Journal. 1990; 301: 1127-1130. 